\title{
Blocking Ca²+-Dependent Synaptic Release Delays Motoneuron Differentiation in the Rat Spinal Cord
}

\author{
Huiwen Xie and Lea Ziskind-Conhaim \\ Department of Physiology and Center for Neuroscience, University of Wisconsin Medical School, Madison, \\ Wisconsin 53706
}

Development of motoneuron electrical properties and excitability was studied in spinal cord explants of rat embryos cultured for 1-3 weeks. The morphological organization of the spinal cord and synaptic inputs onto motoneurons were maintained in organ culture. The rate of differentiation of motoneuron resting potential and increase in membrane excitability was similar in vitro and in vivo, suggesting that these properties were regulated by cellular signals or extracellular differentiation-promoting factors that were preserved in culture. However, maturation of input resistance, action potential threshold and action potential maximum rate of rise was slower than in vivo. Culturing spinal cord explants with their dorsal root ganglia attached did not facilitate motoneuron differentiation.

The role of newly formed synaptic pathways in regulating the changes in motoneuron electrical properties was studied in the presence of blockers of synaptic transmission. Motoneuron differentiation was delayed in spinal cords cultured in the presence of TTX, indicating that electrical activity influenced the time course of their development. However, blocking synaptic transmission with antagonists of glutamate, glycine, and $\mathrm{GABA}_{\mathrm{A}}$ receptors did not affect the rate of motoneuron differentiation, suggesting that maturation of motoneuron phenotype was independent of activation of these transmitter-gated channels. Incubating spinal cords in medium containing high-K ${ }^{+}$, which increased the frequency of spontaneous potentials, reversed the inhibitory effect of TTX. Similar to TTX action, motoneuron development was retarded when synaptic release was chronically blocked with either tetanus toxin or w-conotoxin, a $\mathrm{Ca}^{2+}$ channel blocker. These findings suggested that electrical activity in spinal cord explants modulated motoneuron differentiation via $\mathrm{Ca}^{2+}$-dependent synaptic release of neurotransmitters or neurotrophic factors.

[Key words: activity-dependent mechanism, synaptic release, motoneuron differentiation, motoneuron excitability, electrical properties, organotypic spinal cord]

\footnotetext{
Received Feb. 17, 1995; revised May 19, 1995; accepted May 30, 1995

We thank Dr. Bao-Xi Gao for assisting with some of the experiments, Dr. Peter Lipton for helpful discussions and critical comments on the manuscript, Drs. S.-Y. Chiu and S. Kriegler for helping with confocal microscopy, and Regeneron Inc. for the gift of CNTF This work was supported by NIH Grant NS23808 to L.Z.-C.

Correspondence should be addressed to Lea Ziskind-Conhaim, Department of Physiology, 129 SMI, University of Wisconsin Medical School, 1300 University Avenue, Madison, WI 53706

Copyright 1995 Society for Neuroscience $0270-6474 / 95 / 155900-12 \$ 05.00 / 0$
}

The pattern and time course of neuronal differentiation and synaptogenesis have been studied extensively in spinal cords of embryonic and neonatal rats (Saito, 1979; Smith and IIollyday, 1983; Takahashi, 1984; Kudo and Yamada, 1985, 1987; Fulton and Walton, 1986; 7iskind-Conhaim, 1988, 1990; Wu et al., 1992; Pinco and Lev-Tov, 1993; Ziskind-Conhaim et al., 1993; Seebach and Ziskind-Conhaim, 1994). Some developmental changes in motoneruon electrical and pharmacological properties are temporally correlated with the formation of central and peripheral synapses, but it is not clear whether such changes are governed by cellular information or extracellular factors related to the newly established synaptic pathways. Intracellular recordings in motoneurons developing in vivo have illustrated that: (1) action potential threshold decreases when dorsal root-mediated polysynaptic inputs are established on motoneurons and motor axons first contact their muscles (Ziskind-Conhaim, 1988), (2) motoneuron sensitivity to agonists of glutamate receptors increases at the onset of formation of monosynaptic contacts between dorsal root afferents and motoneurons (Ziskind-Conhaim, 1990), and (3) the characteristics of motoneuron responses to cxogcnous 5-HT changc during cmbryonic development and arc temporally correlated with the growth of descending serotoninergic axons into the ventral horn (7iskind-Conhaim et al., 1993) Such increased excitability and sensitivity to neurotransmitters at the time of increased synaptic activity are functionally important for effective sensorimotor transmission and pattern of motor output.

Newly formed central synapses may regulate motoneuron properties by increasing the level of synaptic activity in the immature spinal cord. Numcrous studics have illustrated that ncuronal differentiation and synaptic plasticity are modulated by activity-dependent mechanisms that involved interlinked preand postsynaptic factors. To determine whether motoneuron differentiation is influenced by the increased synaptic activity in newly formed neuronal pathways, it is essential to alter the level of synaptic transmission in the developing spinal cord. However, in utero manipulations are difficult to control and significantly increase the mortality rate of the embryos. Therefore, several in vitro preparations have been designed as models for spinal cord development in utero. Spinal cord explants cultured in roller tuhes (Spenger et al., 1991; Streit et al., 1991) and Maximov chambers (Crain and Peterson, 1963; Tarrade and Crain, 1978), preserved their functional organization and have been successfully used to study the onset of synaptic activity in the mammalian spinal cord.

In this study, spinal cord explants of rat embryos were maintained in a relatively simple organotypic culture designed by 

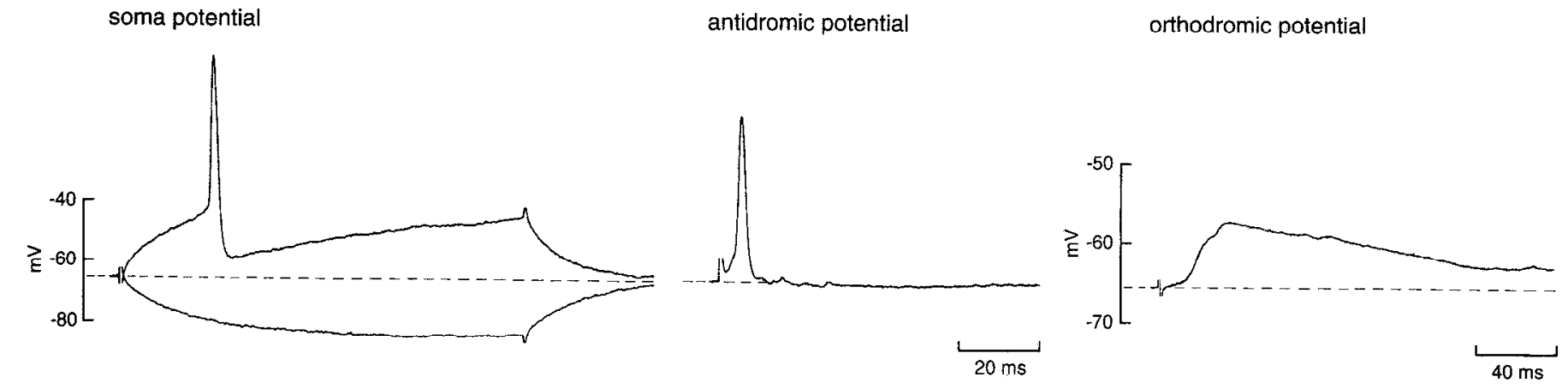

Figure 1. Evoked potentials recorded intracellularly in a motoneuron cultured for $12 \mathrm{~d}$. Soma action potential was generated by intracellular injection of depolarizing current $(0.2 \mathrm{nA})$. Motoneuron input resistance was estimated by measuring the electrotonic potential generated by intracellular injection of hyperpolarizing current $(0.1 \mathrm{nA}$, lower trace). Antidromic and orthodromic potentials were evoked by electrical stimulation of the edges of the ventral and dorsal horns with two extracellular electrodes. Resting membrane potential is indicated by the dashed line.

Stoppini and colleagues (1991). Transverse spinal cord slices were cultured on collagen-coated porous membranes, and in the absence of embedding substances motoneuron impalement with microelectrodes was possible within a few days after explantation. Intracellular recordings and the distribution of dye-labeled motoneurons indicated that the functional and morphological organization of spinal motoneurons was preserved in culture for at least 3 weeks.

The objectives of our study were: (1) to determine whether the time course of differentiation of motoneuron electrical properties and excitability in spinal cord explants paralleled that of motoneurons developing in vivo, and (2) to examine the role of synaptic transmission in regulating motoneuron differentiation.

Brief reports of some of these results have been published previously (Xie and Ziskind-Conhaim, 1993, 1994).

\section{Materials and Methods}

Culturing procedures. Using sterile conditions, lumbar spinal cords were isolated from Sprague-Dawley rat embryos at day 15 of gestation (E15, birth is at E21-E22) following the procedure described previously (Ziskind-Conhaim et al., 1993). The excised spinal cord with attached dorsal root ganglia (DRG) and vertebral column was embedded in $2 \%$ agar, and glued to a Plexiglas chamber filled with cold dissection solution (Takahashi, 1978; Gao and Ziskind-Conhaim, 1994a). The dissecting solution contained (in $\mathrm{mM}$ ): $\mathrm{NaCl}, 139 ; \mathrm{KCl}, 5 ; \mathrm{MgCl}_{2}, 1.1$; $\mathrm{CaCl}_{2}$, 4; HEPES, 4.2; glucose, 11; penicillin, $300 \mu \mathrm{g} / \mathrm{ml}$; streptomycin, $100 \mu \mathrm{g} / \mathrm{ml} ; \mathrm{pH} 7.2-7.3$.

The submerged spinal cord was cut into $300 \mu \mathrm{m}$ transverse slices with a vibrating blade (Vibrotome, Technical Products International, Inc.). The slices were cleaned of the agar and the vertebral column, and transferred onto sterile, porous $(0.4 \mu \mathrm{m})$ membranes coated with collagen (Costar, Inc.). In experiments that were designed to culture spinal cords with their DRG attached, special care was taken not to injure the attached DRG. Membranes with spinal cord explants were placed in 35 $\mathrm{mm}$ wells containing $2 \mathrm{ml}$ of medium which formed a thin layer of fluid over the explants. The explants were incubated in an atmosphere containing $5 \% \mathrm{CO}_{2}$ at $37^{\circ} \mathrm{C}$ for $1-3$ weeks.

One hundred milliliters of culture medium contained $50 \mathrm{ml}$ Dulbecco's modified Eagle medium (GIBCO); $25 \mathrm{ml}$ of Hanks' balanced salt solution (GIBCO); $15 \mathrm{ml}$ of double distilled $\mathrm{H}_{2} \mathrm{O} ; 2.3 \mathrm{ml}$ of $20 \%$ glucose; $1.6 \mathrm{ml}$ of $23.8 \%$ HFPFS, pH 7.2 (Braschler et al., 1989); $8 \%$ heatinactivated fetal bovine serum. To promote the survival of motoneurons and DRG neurons, $50 \mathrm{ng} / \mathrm{ml}$ ciliary neurotrophic factor (Regeneron Pharmaceutical Inc.) and $2 \mathrm{ng} / \mathrm{ml}$ nerve growth factor (Sigma, Co.) were added to the culture medium. Penicillin $(300 \mu \mathrm{g} / \mathrm{ml})$ and streptomycin $(100 \mu \mathrm{g} / \mathrm{ml})$ were added to the medium during the first week in culture. The Inediun was changed twice a week. In different experiments, the following substances were added to the culture medium from the first day of explantation: tetrodotoxin (TTX, Sigma Co.), 6-cyano-7-nitroquinoxaline-2,3-dione (CNQX), 2-amino-5-phosphonovaleric acid (APV), strychnine, bicuculline (Research Biochemicals, Inc.), (RS)- $\alpha$-methyl- 4-carboxyphenylglycine (MCPG, Tocris Neuramin), tetanus toxin (List Biological Laboratories, Inc.), and $\omega$-conotoxin GVIA (Research Biochemicals International).

Electrophysiological recordings. Spinal cord explants attached to the membranes were placed in the recording chamber and were perfused with extracellular solution that was gassed with $5 \% \mathrm{CO}_{2}, 95 \% \mathrm{O}_{2}$ and maintained at $30^{\circ} \mathrm{C}$. The extracellular solution contained (in $\mathrm{mM}$ ): $\mathrm{NaCl}$, 124; $\mathrm{KCl}, 5 ; \mathrm{CaCl}_{2}, 4 ; \mathrm{NaH}_{2} \mathrm{PO}_{4}$, 1.25; $\mathrm{MgSO}_{4}, 2 ; \mathrm{NaHCO}_{3}, 18 ; \mathrm{HE}-$ PES, 5; glucose, 10; pH 7.2-7.3.

Neurons in the lateral and medial ventral horn were impaled with quartz microelectrodes filled with $3 \mathrm{M}$ potassium acetate $(150-250 \mathrm{M} \Omega)$. It was assumed that impaled neurons were motoneurons if a brief $(0.5$ msec) electrical stimulation of the edge of the ventral horn generated antidromic action potential (Fig. 1). Extracellular stimuli at intensities $<3 \mathrm{~V}$ were delivered through glass electrodes (tip diameter of about 10-20 $\mu \mathrm{m}$ ) filled with dissecting solution. Only motoneurons with stable (>30 min) resting membrane potentials more negative than -50 $\mathrm{mV}$ were studied. Synaptic potentials were produced by a brief electrical stimulation $(<1 \mathrm{~V})$ of the dorsal horn or DRG with a second glass electrode.

Motoneuron membrane resistance was estimated by measuring the electrotonic potential evoked by intracellular injection of small $(0.1-0.2$ nA) hyperpolarizing currents (Fig. 1). To estimate the action potential threshold, a series of depolarizing currents was injected intracellularly, and the threshold was recorded at the lowest intensity that generated a soma action potential. The maximum rate of rise of the action potential was analyzed digitally. Data are presented as mean \pm SE. The statistical significance of differences of the means was evaluated using the Student's $t$ test.

Motoneuron staining. Distribution of dye-labeled motoneurons was examined by staining them with 1,1'-dioctadecyl-3,3,3',3'-tetramethylindo-carbocyanin (DiI, Sigma, Co.). Spinal cord slices were washed with phosphate buffered saline (PBS), and fixed overnight with $4 \%$ paraformaldehyde at $4^{\circ} \mathrm{C}$. Small crystals of DiI were plaecd on distal processes growing from the ventral horn and the DRG (Snider et al., 1992). The slices were maintained in the fixative solution at $37^{\circ} \mathrm{C}$, and were examined daily to evaluate the spread of the dye. Within 5-10 d, the slices were washed and photographed with an epiffuorescence microscope (Nikon, Co.) or a confocal microscope (Noran Odyssey).

\section{Results}

\section{Morphological organization of spinal cord explants}

Spinal cord explants maintained their shape and size, and even after 3 weeks in culture their thickness was about $200 \mu \mathrm{m}$. Explant flattening probably reflected the loss of cell layers, but its extent was smaller than that of spinal cord explants cultured in roller tubes (Spenger et al., 1991), and that of neonatal hippocampal slices cultured on membranes similar to those used in our study (Stoppini et al., 1991). Processes grew out of the ventral horn and DRG within 2-3 $\mathrm{d}$ in culture. In about $97 \%$ of explants retrogradely labeled with DiI, clustcrs of ncurons were stained in the lateral and medial ventral horn (Fig. $2 b$ ) at loca- 

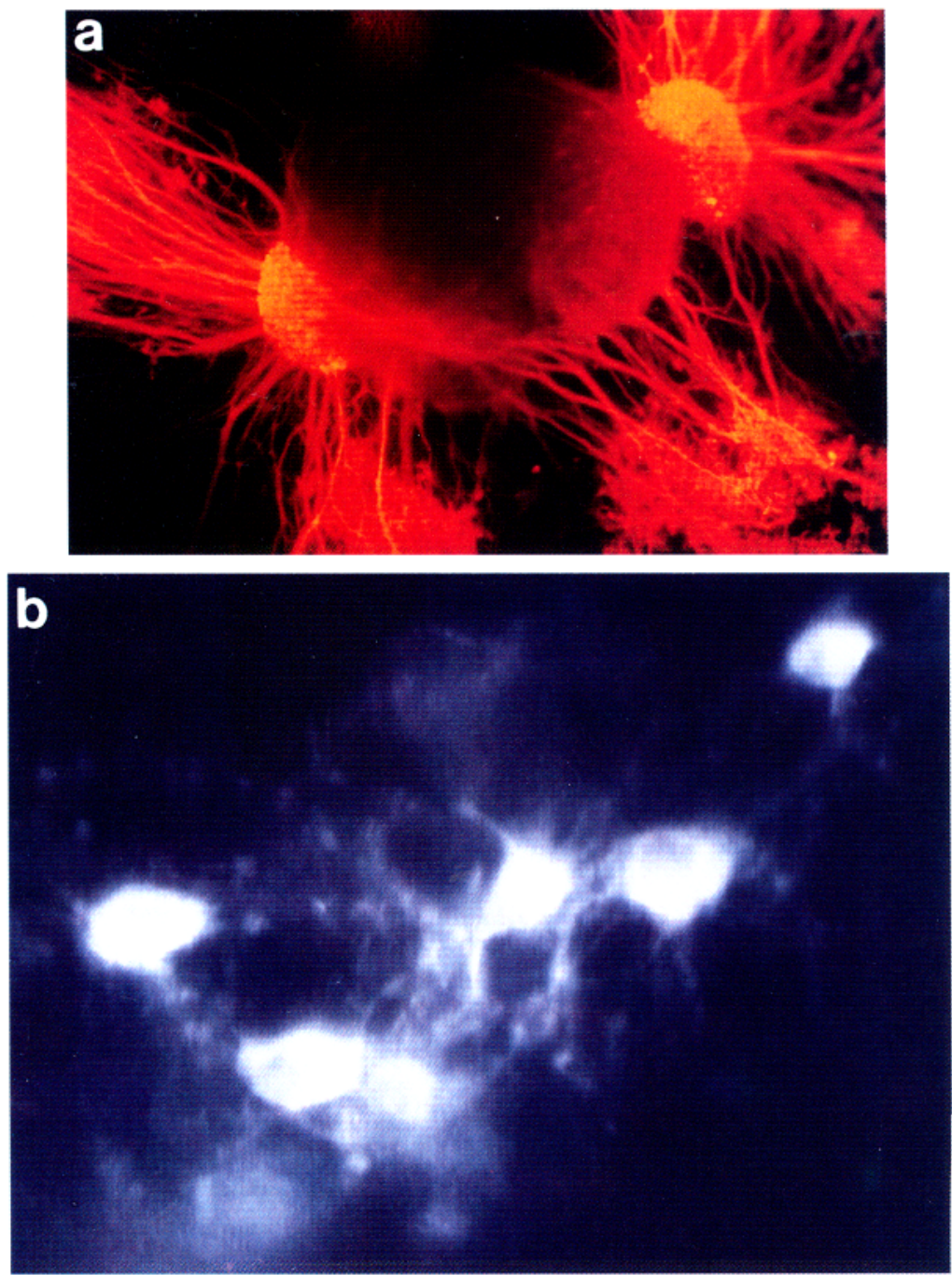

Figure 2. Micrographs of spinal cord explant and motoneurons cultured for 1-2 weeks. $a$, DiI-labeled neurites extended from the ventral horn and DRG. Neurons in the DRG were brightly labeled with DiI. $b$, A cluster of motoneurons at the lateral edge of the ventral horn. Motoneurons were retrogradely labeled with DiI and visualized with a confocal microscope. Ventral is down and lateral is right. $c$, DiI-labeled motoneuron with its extensive dendritic field. Scale bar: $a, 530 \mu \mathrm{m} ; b, 60 \mu \mathrm{m}$; $c, 70 \mu \mathrm{m}$.

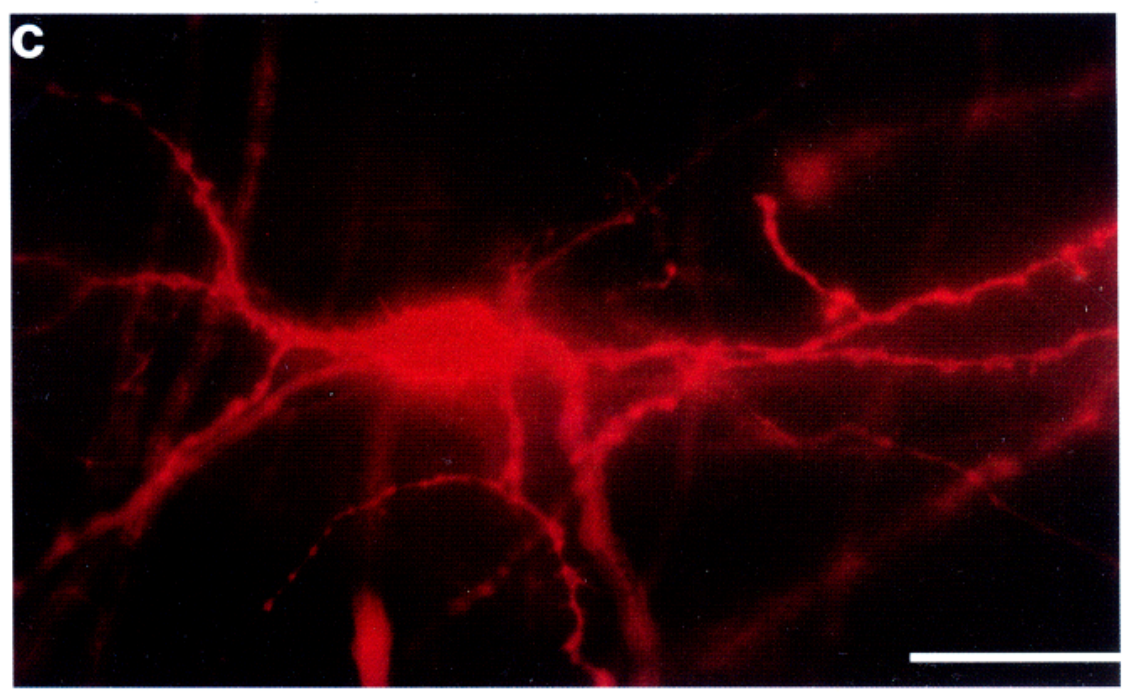

tions similar to those described for spinal motoneurons developing in vivo (Smith and Hollyday, 1983; Ziskind-Conhaim, 1990; Ziskind-Conhaim and Presley, 1991). DiI-labeled spinal neurons were located only in the ventral horn, suggesting that the processes growing out of the spinal cord were motor axons and the labeled neurons were motoneurons. Motoneuron somata varied greatly in size $(20-40 \mu \mathrm{m}$ in diameter), and many diIlabeled motoneurons had extensive dendritic fields (Fig. 2c). It is unlikely that motoneurons migrated out of the spinal cord, because DiI-labeled cells were not detected outside the spinal cord. Moreover, the finding that the unidentified round cells, which were sometimes apparent outside the spinal cord were not 


\section{E15}

\section{$E 15+1 W k$}

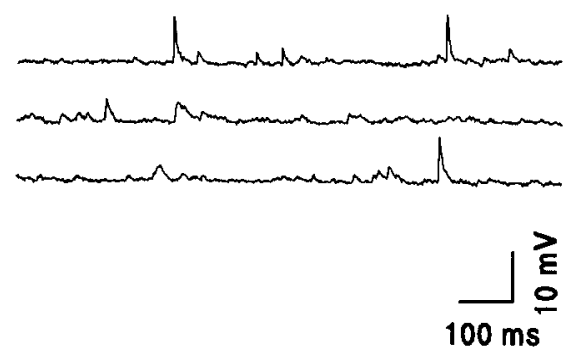

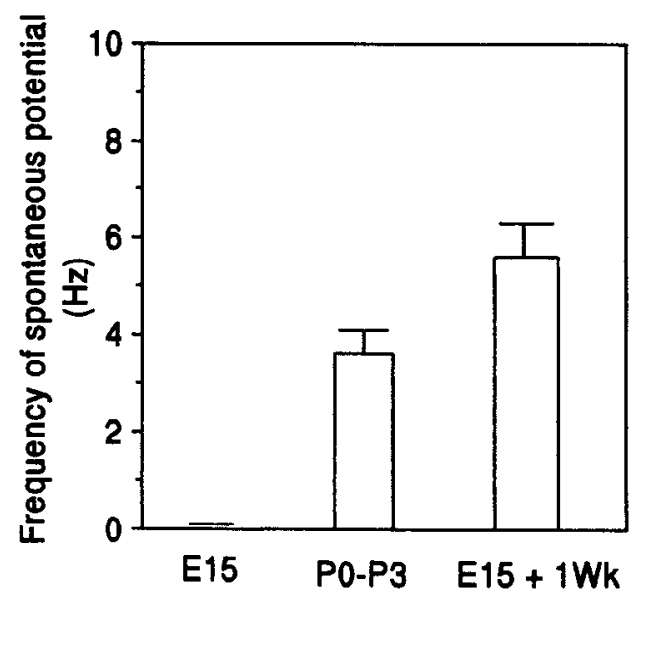

Figure 3. The frequency of spontaneous potentials increased in motoneurons cultured for one week. $a$, Traces of continuous intracellular recordings of spontaneous potentials in an E15 motoneuron, and a motoneuron cultured for 1 week $(E 15+1 W k)$. Resting membrane potentials were $-57 \mathrm{mV}$ at $\mathrm{E} 15$ and $-62 \mathrm{mV}$ at E15+1Wk. $b, \mathrm{~A}$ histogram of the frequency of spontaneous potentials as a function of developmental age and time in culture. At E15 the frequency of spontaneous potentials was $<0.05 \mathrm{~Hz}(n=13)$, and it increased to $3.7 \mathrm{~Hz}$ at P0-P3 $(n=12)$. The frequency of spontaneous potentials in motoneurons cultured for 1 week was $5.8 \mathrm{~Hz}(n=21)$, significantly higher $(P<0.05)$ than that of neonatal motoneurons. Data are presented as mean $\pm \mathrm{SE}$. stained with Dil, ruled out the possibility that they contributed to the extensive growth adjacent to the spinal cord.

In spinal cord explants with attached DRG, placement of DiI crystals on processes growing out of the DRG, brightly stained DRG neurons (Fig. 2a). DiI-labeled DRG neurites grew in all directions, and extended into the spinal cord. Immunocytochemical labeling with antibodies to calcitonin gene related peptide and substance $P$ illustrated that small diameter DRG projections entered the spinal cord and arborized in the dorsal horn, but did not enter the ventral horn (Redmond et al., 1994).

\section{Development of synaptic pathways in spinal cord explants}

The frequency of spontaneous potentials was recorded in motoneurons cultured for 1-3 weeks (E15 + 1-3 Wk), which corresponded to postnatal days $0-14$ (P0-P14) in vivo. A similar pattern of tonic spontaneous activity characterized motoneurons developing in vivo and in vitro, and at resting membrane potential only depolarizing potentials were recorded (Figs. 3, 4a). The frequency of spontaneous potentials was measured during continuous recordings that lasted $>30 \mathrm{sec}$ (Figs. 3, 4a). At E15, the frequency was $<0.05 \mathrm{~Hz}$ and it remained low throughout embryonic development. Significantly higher frequencies were recorded within a few days after birth (about $4 \mathrm{~Hz}, \mathrm{P}$ )-P3 Fig. 3 ), and after 1 week in culture (about $6 \mathrm{~Hz}, \mathrm{E} 15+1 \mathrm{Wk}$ Fig. 3 ). The frequency of spontaneous potentials did not increase, and it remained at $6 \mathrm{~Hz}$ during the second and third week in culture. The elevated spontaneous activity suggested that compared to spinal cord developing in vivo, there was a significant increase in the number of synaptic connections or in the efficacy of synaptic transmission in spinal cords developing in culture.

Studying the synaptic nature of the spontaneous potentials demonstrated that they consisted of both excitatory postsynaptic potentials (EPSPs) and potentials that reversed at membrane potential of about $-50 \mathrm{mV}$ (Fig. $4 b$ ). These findings suggested the latter were depolarizing inhibitory postsynaptic potentials (IPSPs), similar to those that have been recorded in embryonic and neonatal spinal cords (Jahr and Yoshioka, 1986; Gao and Ziskind-Conhaim, 1994a; Seebach and Ziskind-Conhaim, 1994). The transition from depolarizing to hyperpolarizing IPSPs did not occur in motoneurons cultured for up to 3 weeks, while the in vivo transition occurs between $2-3$ weeks after birth (Takahashi, 1984; Jiang et al., 1990).

Disinhibition with strychnine $(10 \mu \mathrm{M})$ and bicuculline $(20$ $\mu \mathrm{M})$, antagonists of glycine and $\mathrm{GABA}_{\mathrm{A}}$ receptors, induced bursts of long-lasting depolarizing potentials (Fig. 4c) similar to the pattern generated in spinal cords developing in vivo ( $\mathrm{Wu}$ et al., 1992). The spontaneous potentials were completely blocked by APV $(20 \mu \mathrm{M})$ and CNQX $(10 \mu \mathrm{M})$, antagonists of NMDA and non-NMDA receptors (Fig. 4c), implying that they were mediated via glutamate-activated synapses. These findings supported previous reports illustrating that antagonists of NMDA and non-NMDA receptors block spontaneous and dorsal rootevoked synaptic potentials in the rat spinal cord developing in vivo (Jiang et al., 1990; Pinco and Lev-Tov, 1992; Ziskind-Conhaim et al., 1993), and in organ culture (Streit and Luscher, 1992).

Evoked synaptic potentials were not studied qualitatively, but electrical stimulation of the dorsal horn or DRG produced subthreshold synaptic potentials (Fig. 1). Similar to the spontaneous potentials, the evoked potentials were completely blocked by APV $(20 \mu \mathrm{M})$ and CNQX $(10 \mu \mathrm{M}$, not shown), indicating that they were mediated via glutamate-activated synaptic pathways.

\section{Differentiation of motoneuron electrical properties and excitahility}

To examine the developmental changes in motoneuron electrical properties, resting membrane potential, input resistance, action potential threshold and maximum rate of rise were examined in acutely isolated spinal cord slices $(300 \mu \mathrm{m})$ of embryonic (E15) and postnatal (P0-P3) motoneurons. During the last week in utero, motoneuron resting potential became more negative, input resistance and threshold for action potential decreased, and action potential maximum rate of rise increased (Table 1). Similar changes in motoneuron properties were recorded in hemisected spinal cords of embryonic and neonatal rats (Ziskind-Conhaim, 1988).

To determine whether the time course of motoneuron differentiation in culture was similar to that in vivo, changes in motoneuron electrical properties were analyzed within $1-3$ weeks in culture. After 1 week in culture, resting membrane potential 

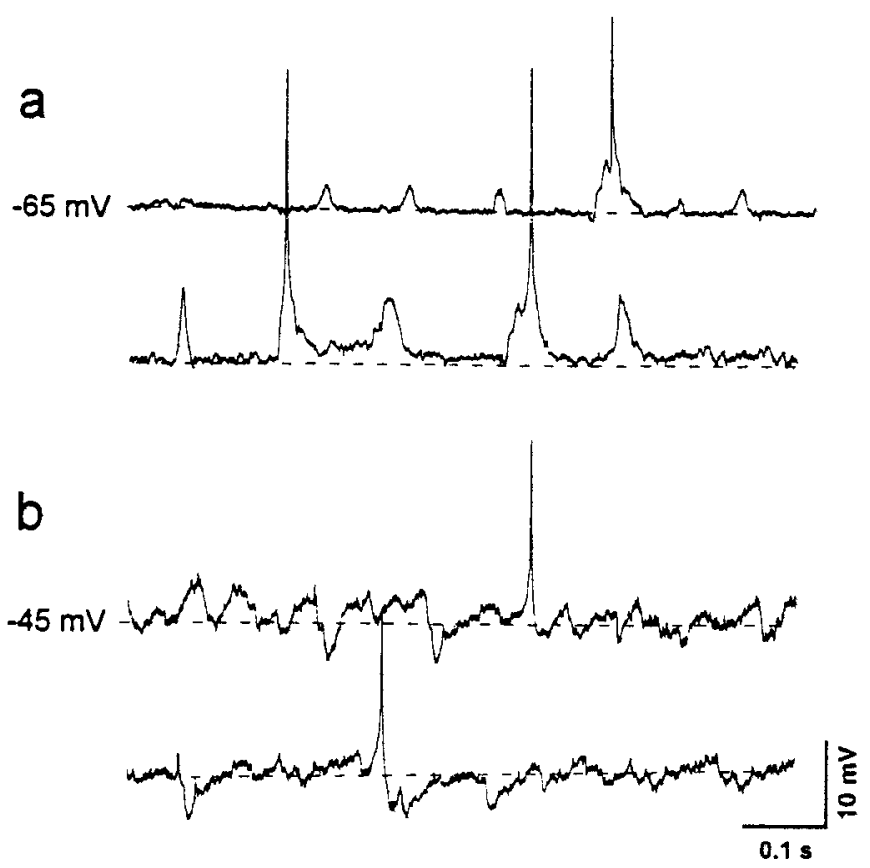

C

normal
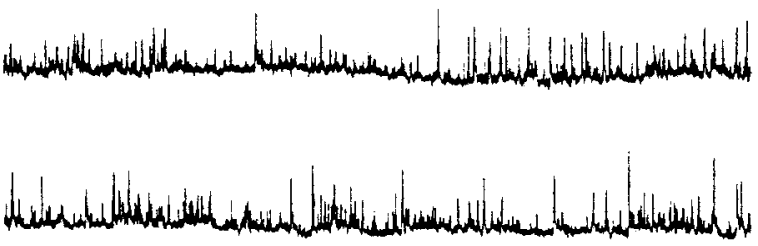

strychnine + bicuculline

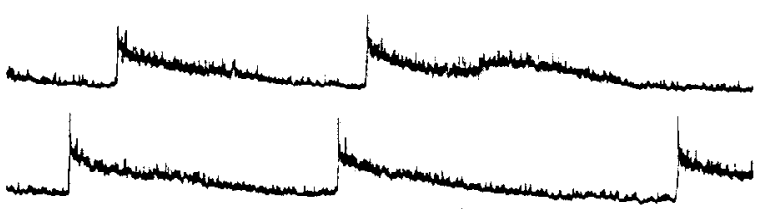

$\mathrm{APV}+\mathrm{CNQX}$

+ strychnine + bicuculline was the only property that was similar to that of neonatal motoneurons (Table 1). Although during the first week in culture the changes in action potential threshold and maximum rate of rise developed slower than in motoneurons differentiating in vivo, these properties were significantly different from those of E15 motoneurons (Table 1). By the second and third week in culture, motoneuron properties were similar to those of neonatal motoneurons.

The decrease in membrane resistance probably reflects an increase in motoneuron size (Kernell and Zwaagstra, 1981; Hochner and Spira, 1987). The decrease in threshold for action potential results from developmental changes in voltage-dependent inward and outward currents (Gao and Ziskind-Conhaim, $1993 \mathrm{~b}, \mathrm{~b})$, and the increase in action potential rate of rise is correlated with an increase in $\mathrm{Na}^{+}$channel density (MacDermott and Westbrook, 1986; McCobb et al., 1992; Gao and ZiskindConhaim, 1993b). The slow development of these properties implied that cellular or extracellular factors that promoted their differentiation were partially absent in organ culture.

Motoneuron excitability increased after birth as evident by the increased probability of generating repetitive action potentials in response to a sustained intracellular injection of depolarizing current (Fulton and Walton, 1986; Gao and Ziskind-Conhaim, 1994b). In embryonic motoneurons, current injection generated only one action potential, while similar current produced a train of action potentials in about $40 \%$ of neonatal motoneurons (Fig. 5). To compare the excitability of cultured motoneurons to that of motoneurons developing in vivo, motoneuron ability to fire repetitively was studied after $1-3$ weeks in culture. Within 1 week in culture, $47 \%$ of motoneurons generated repetitive action potentials (Fig. 5), and by the third week $89 \%$ of them were capable of producing a sustained train of action potentials. These findings suggested that parallel increase in motoneuron excitability occurred in culture and in vivo.

Differentiation of motoneuron electrical properties was independent of the presence of dorsal root ganglia

To determine whether dorsal root ganglia (DRG) facilitated the development of motoneuron electrical properties, those properties were examined in spinal cord explants cultured with DRG attached. After 1 week in culture, most motoneuron properties in spinal cord-DRG explants were different from those of E15 motoneurons, but similar to those of motoneurons in spinal cords cultured without DRG (Table 2). Motoneurons gradually acquired their mature properties independently of the presence of the DRG, and after 2-3 weeks in culture there was no significant difference between the properties of motoneurons cultured with or without DRG attached (Table 2).

The frequency of spontaneous potentials in spinal cord-DRG explants was similar to that recorded in spinal cord explants cultured in the absence of DRG, suggesting that the growth of DRG projections into the spinal cord did not affect synaptic

$\leftarrow$

Membrane depolarization to $-45 \mathrm{mV}$ was produced by a D.C. current injection. In a different motoncuron (c), high-frcquency potentials werc recorded in normal extracellular solution (normal), and disinhibition produced by strychnine $(10 \mu \mathrm{M})$ and bicuculline $(20 \mu \mathrm{M})$ resulted in periodic bursts of long-lasting depolarizing potentials. The spontaneous potentials were completely blocked by APV $(20 \mu \mathrm{M})$ and CNQX (10 $\mu \mathrm{M})$. Resting membrane potential was $-64 \mathrm{mV}$. In $a$ and $b$ membrane potentials are marked by the dashed line, and potentials were recorded at a slow sampling intervals (200 $\mu \mathrm{sec})$.
Figure 4. Continuous traces of spontaneous potentials recorded in a motoneuron cultured for 2 weeks. At resting membrane potential $(-65$ $\mathrm{mV}$ ), only depolarizing potentials were recorded $(a)$, but hyperpolarizing potentials were apparent at membrane potential of $-45 \mathrm{mV}(b)$. 


\begin{tabular}{lllll}
\hline \multicolumn{4}{l}{ Table 1. Slow differentiation of motoneuron electrical properties in spinal cord explants } \\
$\begin{array}{l}\text { Age in vivo and } \\
\text { time in vitro }\end{array}$ & $\begin{array}{l}\text { Resting potential } \\
(\mathrm{mV})\end{array}$ & $\begin{array}{l}\text { Input resistance } \\
(\mathrm{M} \Omega)\end{array}$ & $\begin{array}{l}\text { Threshold potential } \\
(\mathrm{mV})\end{array}$ & $\begin{array}{l}\text { Max. rate of rise } \\
(\mathrm{V} / \mathrm{sec})\end{array}$ \\
\hline $\mathrm{E} 15$ & $\begin{array}{l}-57.9 \pm 0.09^{*} \\
(n=13)\end{array}$ & $125.0 \pm 5.8^{*}$ & $-28.2 \pm 1.0^{*}$ & $6.5 \pm 0.6^{*}$ \\
$\mathrm{P} 0-\mathrm{P} 3$ & $\begin{array}{l}-65.2 \pm 1.3 \\
(n=12)\end{array}$ & $73.4 \pm 4.4$ & $-43.6 \pm 1.5$ & $39.3 \pm 3.8$ \\
$\mathrm{E} 15+1 \mathrm{Wk}$ & $\begin{array}{l}-63.0 \pm 0.6 \dagger \\
(n=21)\end{array}$ & $122.1 \pm 7.3^{*}$ & $-39.0 \pm 0.7^{* * \dagger}$ & $26.9 \pm 1.3^{* \dagger}$ \\
$\mathrm{E} 15+2 \mathrm{Wk}$ & $\begin{array}{l}-63.0 \pm 0.9 \\
(n=22) \\
\text { E15 }\end{array}$ & $105.4 \pm 5.2^{*}$ & $-40.0 \pm 0.6^{* * *}$ & $34.8 \pm 2.2$ \\
& $\begin{array}{l}-63.1 \pm 0.6 \\
(n=22)\end{array}$ & $83.5 \pm 5.9$ & $-41.6 \pm 0.9$ & $35.1 \pm 1.5$ \\
\end{tabular}

Electrical properties of motoneurons cultured for 1-3 weeks were compared with those of embryonic (E15) and postnatal (P0-P3) motoneurons. One week in culture (E15 $+1 \mathrm{Wk})$ corresponded to postnatal days $0-1$ (P0-P1). Within 1 week in culture, only membrane resting potential developed at a rate similar to that in vivo. Differentiation of input resistance and action potential threshold and maximum rate of rise was slower in culture than in vivo, but within 3 weeks in culture $(\mathrm{E} 15+3 \mathrm{Wk})$ these properties were similar to those of postnatal motoneurons. Data are presented as mean $\pm \mathrm{SE} ; n$, number of motoneurons.

* Significantly different from postnatal neurons $(p<0.001)$.

**Significantly different from postnatal neurons $(p<0.01)$.

***Significantly different from postnatal neurons $(p<0.05)$.

$\dagger \mathrm{t} 15+1 \mathrm{Wk}$ motoneurons which were significantly different from E15 motoneurons $(p<0.001)$.

transmission. Although DRG projections grew into the spinal cord, spinal reflex pathways were incomplete in spinal cord explants, and the frequency of excitation of DRG neurons was probably low in the absence of sensory inputs from the muscle and skin. In spinal cord-DRG explants, spontaneous action potentials were not recorded in DRG neurons, even though the neurons were excitable and generated action potentials in response to intracellular current injections (not shown). Similar results have been reported in spinal cord-DRG-muscle cultures, in which spontaneous action potentials were recorded only in about $2 \%$ of DRG neurons, and those were correlated with intense muscle contraction (Streit et al., 1991).

\section{Effects of blocking electrical activity and synaptic transmission on motoneuron differentiation}

To examine the role of electrical activity in modulating motoneuron electrical properties and excitability, action potentials were chronically blocked by adding TTX $(1 \mu \mathrm{M})$ to the culture medium. Suppression of electrical activity in spinal cord explants prolonged the delayed differentiation of motoneuron electrical properties (Table 3). Although action potential threshold decreased and maximum rate of rise increased compared to E15 motoneurons, their development was slower than in motoneurons cultured in normal medium. Only after 3 weeks in TTXcontaining medium, motoneuron properties were similar to those of motoneurons cultured for 1 week in normal medium. Similarly, all motoneurons retained their embryonic inability to fire repetitively, and after the first week in culture only one action potential was produced in response to a prolonged depolarizing current (Fig. 6). By the second week in culture, 29\% of motoneurons fired repetitively compared to $65 \%$ of motoneurons in spinal cord explants maintained in normal medium.

To determine whether TTX-induced delayed differentiation resulted from inhibition of synaptic transmission, glutamate-mediated excitatory synapses were blocked with antagonists of glutamate receptors. Culturing spinal cord explants in the presence of APV $(20 \mu \mathrm{M})$ and CNQX $(10 \mu \mathrm{M})$ completely blocked spon- taneous potentials in motoneurons (Fig. 4c), but did not delay the development of motoneuron electrical properties (Table 4). Similarly, blocking metabotropic glutamate receptors with the selective antagonist MCPG $(500 \mu \mathrm{M}$, Eaton et al., 1993), did not affect the time course of motoneuron differentiation.

To further evaluate the function of synaptic transmission in motoneuron development, the level of synaptic activity was increased by blocking glycine- and $\mathrm{GABA}_{\mathrm{A}}$-mediated inhibitory synaptic pathways. Spinal cord explants were maintained in the presence of strychnine $(10 \mu \mathrm{M})$ and bicuculline $(20 \mu \mathrm{M})$, and although the induced disinhibition produced prolonged bursts of synaptic potentials (Fig. 4c), it did not affect the rate of motoneuron differentiation (Table 4). Similarly, blocking both excitatory and inhibitory synaptic transmission did not delay the maturation of motoneuron electrical properties (not shown), indicating that motoneuron differentiation was independent of activation of excitatory and inhibitory amino acids receptors. Simultaneous inhibition of both electrical activity (TTX) and synaptic transmission with a mixture of APV, CNQX, strychnine and bicuculline (solution $B$ ) resulted in a delayed differentiation similar to that produced by TTX alone (Table 4).

\section{Blocking $\mathrm{Ca}^{2+}$-dependent synaptic release delayed motoneuron differentiation}

Electrical inactivity affected both action potential-dependent synaptic release and depolarization-mediated postsynaptic events. To test the possibility that TTX-induced delayed differcntiation resulted from blocking presynaptic release of neurotransmitters or neurotrophic factors, spinal cords were cultured in the presence of high extracellular $\mathrm{K}^{+}(20 \mathrm{~mm})$ which depolarized motoneurons by about $20 \mathrm{mV}$, and significantly increased the frequency of TTX-resistant spontaneous potentials (Gao and Ziskind-Conhaim, unpublished observations). High-K ${ }^{+}$effectively reversed the delayed development induced by TTX, and the rate of motoneurons differentiation in spinal cord explants cultured in high-K+ $\mathrm{K}^{+}$and a mixture of TTX, APV, CNQX, strych- 
a

\section{E15}
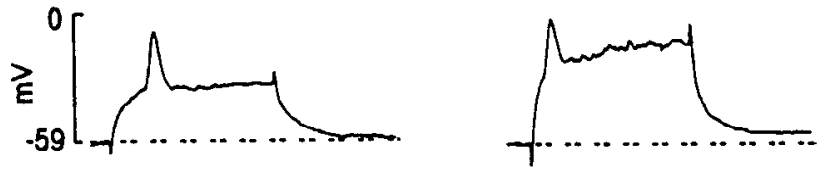

P1
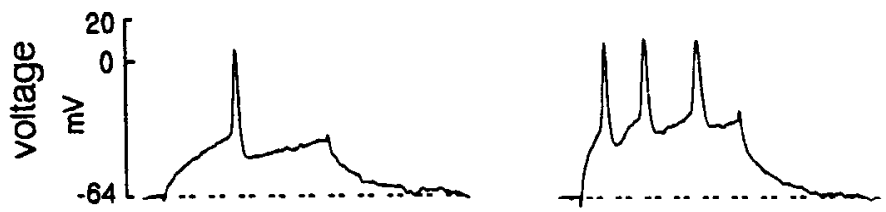

E15+1WK
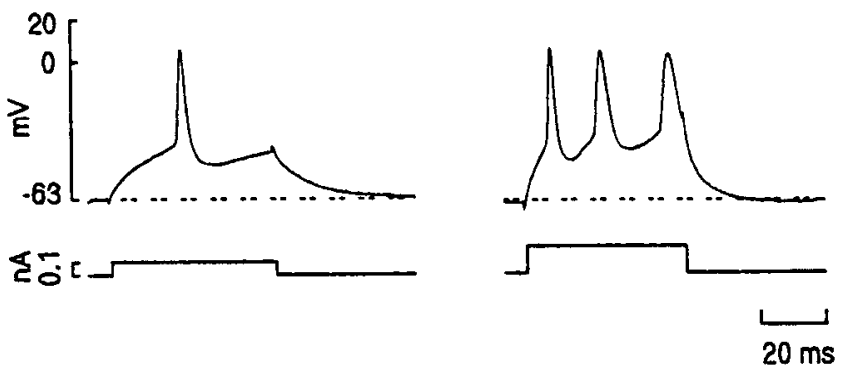

b

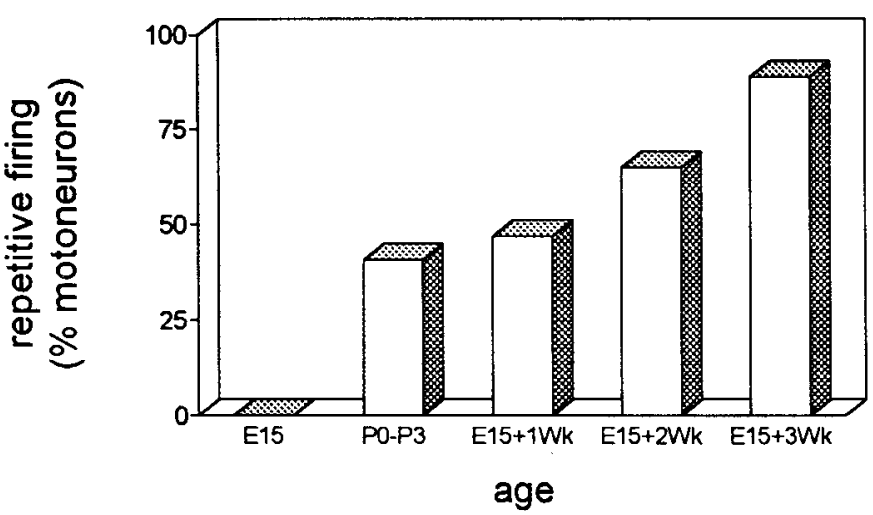

Figure 5. Motoneuron excitability increased in spinal cord explant, and repetitive action potentials similar to those generated in postnatal motoneurons were generated in motoneurons cultured for 1 week. $a$, In E15 motoneuron, a prolonged intracellular injection of depolarizing current $(0.1 \mathrm{nA}$, bottom left trace) produced only one action potential, even at twofold increased current intensity $(0.2 \mathrm{nA}$, bottom right trace). However, in a motoneuron of postnatal rat $(P I)$ and a motoneuron cultured for 1 week $(E 15+1 W k)$, similar currents $(0.2 \mathrm{nA})$ produced three action potentials. Resting potentials are indicated by the dashed lines. $b$, The histogram illustrates the percentage of motoneurons firing repetitively as a function of age in vivo and time in culture. E15 motoneurons were not capable of generating more than one action potential in response to intracellular current injection $(n=13)$. After birth $(P 0-P 3), 41 \%$ of motoneurons fired repetitively $(n=12)$, and after the first week in culture $(E I 5+1 W k) 47 \%$ of them generated a sustained train of action potentials $(n=21)$. Motoneuron excitability continued to increase with nine, and bicuculline was similar to that of motoneurons cultured in normal medium (Table 5, Fig. 6).

It is conceivable that high- $\mathrm{K}^{+}$reversed TTX action by directly depolarizing motoneurons rather than increasing synaptic release. Therefore, in another series of experiments, presynaptic release was irreversibly blocked by chronic application of tetanus toxin $(2 \mu \mathrm{g} / \mathrm{ml}$, Habermann and Dreyer, 1986; Williamson et al., 1992), that suppressed spontaneous potentials in the cultured motoneurons. Tetanus toxin delayed motoneuron differentiation, and after 1 week in culture motoneuron electrical properties and excitability were similar to those of motoneurons cultured in the presence of TTX (Table 5, Fig. 6). These findings suggested that presynaptic release of neurotransmitters or neurotrophic factor(s) played a dominant role in modulating the rate of motoncuron differentiation.

To determine whether synaptic release of neurotrophic factors was $\mathrm{Ca}^{2+}$-dependent, synaptic transmission was blocked by $\omega$-conotoxin GVIA, a specific blocker of $\mathrm{N}$-type voltage-gated $\mathrm{Ca}^{2+}$ channels in chick DRG neurons (Aosaki and Kasai, 1989; Cox and Dunlap, 1992; but see McCleskey et al., 1987). Activation of these channels triggers excitatory synaptic transmission between DRG neurons and spinal neurons in the developing mouse and chick (Yu et al., 1992; Gruner and Silva, 1994). In spinal cord explants, spontaneous potentials were irreversibly blocked by $\omega$-conotoxin GVIA $(1 \mu \mathrm{M})$, and after 1 week in culture motoneurons retained their embryonic properties to resemble those of motoneurons cultured in TTX-containing medium (Table 5). These data suggested that the regulatory signals that influenced the rate of motoneuron maturation were released presynaptically via activation of $\omega$-conotoxin-sensitive $\mathrm{Ca}^{2+}$ channels.

$\omega$-Conotoxin effectively delayed the differentiation of motoneuron electrical properties, but it was less effective than TTX and tetanus toxin in slowing the rate of developmental increase in motoneuron excitability. After one week exposure to $\omega$-conotoxin, about $20 \%$ of motoneurons were capable of generating repetitive action potentials, while none fired repetitively in spinal cord explants cultured in TTX- and tetanus toxin-containing media (Fig. 6). It is possible that regulation of motoneuron excitability was not mediated solely via activation of $\omega$-conotoxinsensitive $\mathrm{Ca}^{2+}$ channels, and the release of neurotrophic substances by $\mathrm{Ca}^{2+}$-independent mechanism may have contributed to the differentiaiton of motoneuron excitability.

\section{Discussion}

In spinal cord explants, motoneuron excitability increased at a rate similar to that in vivo, but differentiation of most electrical properties was delayed. Our findings suggested that $\mathrm{Ca}^{2+}$-dependent release of neurotransmitters or neurotrophic factors from presynaptic terminals played an important role in regulating the time course of motoneuron differentiation.

\section{Functional organization of spinal cord explants}

Spinal cord explants maintained their shape and size, and synaptic pathways remained intact as evident by the increased frequency of spontaneous potentials and the generation of synaptic potentials in response to electrical stimulation of the dorsal horn

$$
\leftarrow
$$

time in culture, and $65 \%$ and $89 \%$ of motoneurons fired repetitively after $2(n=22)$ and 3 weeks in culture $(n=22)$. 
Table 2. Differentiation of motoneuron electrical properties was independent of dorsal root ganglia

\begin{tabular}{rllll} 
DRG & $\begin{array}{l}\text { Resting potential } \\
(\mathrm{mV})\end{array}$ & $\begin{array}{l}\text { Input resistance } \\
(\mathrm{M} \Omega)\end{array}$ & $\begin{array}{l}\text { Threshold potential } \\
(\mathrm{mV})\end{array}$ & $\begin{array}{l}\text { Max. rate of rise } \\
(\mathrm{V} / \mathrm{sec})\end{array}$ \\
\hline$(+) 1 \mathrm{Wk}$ & $\begin{array}{l}-62.8 \pm 1.0 \\
(n=8)\end{array}$ & $125.8 \pm 8.3$ & $-39.2 \pm 0.9$ & $27.2 \pm 3.0$ \\
$2 \mathrm{Wk}$ & $\begin{array}{l}-63.7 \pm 1.0 \\
(n=12)\end{array}$ & $106.3 \pm 7.2$ & $-40.3 \pm 0.7$ & $34.9 \pm 3.1$ \\
$3 \mathrm{Wk}$ & $\begin{array}{l}-63.4 \pm 0.9 \\
(n=13)\end{array}$ & $81.7 \pm 7.4^{* * * *}$ & $-43.0 \pm 1.1^{*}$ & $34.8 \pm 1.8^{*}$ \\
$(-) 1 \mathrm{Wk}$ & $\begin{array}{l}-63.0 \pm 0.7 \\
(n=13)\end{array}$ & $121.1 \pm 3.8$ & $-39.0 \pm 0.8$ & $26.8 \pm 1.8$ \\
$2 \mathrm{Wk}$ & $\begin{array}{l}-62.3 \pm 1.0 \\
(n=10)\end{array}$ & $103.4 \pm 6.0 \dagger$ & $-39.8 \pm 0.5$ & $34.6 \pm 3.1 \dagger$ \\
$3 \mathrm{Wk}$ & $\begin{array}{l}-62.9 \pm 0.7 \\
(n=9)\end{array}$ & $86.1 \pm 10.1 \dagger$ & $-39.6 \pm 1.3$ & $35.6 \pm 2.7 \dagger$
\end{tabular}

Differentiation of motoneuron electrical properties was not facilitated in the presence of DRG. Motoneuron development continued in spinal cord explants, and the time course of their maturation was similar in the presence $(+)$ and absence $(-)$ of DRG. Data are presented as mean $\pm \mathrm{SE} ; n$, number of motoneurons.

* Significantly different from motoneurons cultured for 1 week with DRG attached $(p<0.05)$.

* * Significantly different from motoneurons cultured for 2 weeks with DRG atiached $(p<0.05)$.

$\uparrow$ Significantly different from motoneurons cultured for 1 week without DRG $(p<0.05)$.

and DRG. High-frequency spontaneous potentials have also been recorded in explants of mouse spinal cord cultured in Maximov chambers (Tarrade and Crain, 1978), and in slices of rat spinal cord maintained in roller tubes (Streit and Luscher, 1992).

Low-frequency spontaneous potentials characterizes embryonic motoneurons, despite the early formation of sensory-motoneuron synapses (Saito, 1979; Kudo and Yamada, 1987; Ziskind-Conhaim, 1990). Within 1 week in culture the frequency increased to about $6 \mathrm{~Hz}, 50 \%$ higher than that recorded in postnatal motoneurons of comparable age. The higher frequency in vitro could have resulted from the formation of more synaptic contacts, or the existence of more active presynaptic neurons. It is possible that abundant, new synaptic connections were formed because of the reduced level of electrical activity in the incomplete spinal reflex pathways. The effect of electrical activity on neuronal growth has been demonstrated in dissociated mouse DRG neurons in which phasic pattern of electrical stimulation slows neurite outgrowth, while TTX reverses this effect (Fields et al., 1990; but see Nelson et al., 1990). It is also possible that signals from descending supraspinal projections and target muscles downregulated the number of synaptic pathways in spinal cords developing in vivo, and in the absence of such projections, numerous segmental synaptic connections were formed in spinal cord explants.

\section{Differentiation of motoneuron electrical properties and excitability}

The slow maturation of motoneuron electrical properties in spinal cord explants indicated that some cellular or extracellular differentiation-promoting factors, which were responsible for sustaining

Table 3. Activity-dependent differentiation of motoneuron electrical properties

\begin{tabular}{|c|c|c|c|c|}
\hline Age & $\begin{array}{l}\text { Resting potential } \\
(\mathrm{mV})\end{array}$ & $\begin{array}{l}\text { Input resistance } \\
(\mathrm{M} \Omega)\end{array}$ & $\begin{array}{l}\text { Threshold potential } \\
(\mathrm{mV})\end{array}$ & $\begin{array}{l}\text { Max. rate of rise } \\
\text { (V/sec) }\end{array}$ \\
\hline E15 & $\begin{array}{l}-57.9 \pm 0.9^{*} \\
(n=13)\end{array}$ & $125.0 \pm 5.8$ & $-28.2 \pm 1.0^{*}$ & $6.5 \pm 0.6^{*}$ \\
\hline $\begin{array}{c}\mathrm{E} 15+1 \mathrm{Wk} \\
\text { normal }\end{array}$ & $\begin{array}{l}-63.0 \pm 0.6 \\
(n=21)\end{array}$ & $122.1 \pm 7.3$ & $-39.0 \pm 0.7$ & $26.9 \pm 1.3$ \\
\hline $\begin{array}{l}\mathrm{E} 15+1 \mathrm{Wk} \\
\mathrm{TTX}\end{array}$ & $\begin{array}{l}-57.2 \pm 1.8^{*} \\
(n=9)\end{array}$ & $130.4 \pm 8.9$ & $-36.0 \pm 1.1^{* * \dagger}$ & $13.3 \pm 1.2 * \dagger$ \\
\hline $\begin{array}{l}\mathrm{E} 15+3 \mathrm{Wk} \\
\text { TTX }\end{array}$ & $\begin{array}{l}-61.1 \pm 0.6 \ddagger \\
(n=10)\end{array}$ & $117.8 \pm 6.5$ & $-38.7 \pm 0.7 \dagger$ & $25.5 \pm 1.5 \dagger$ \\
\hline
\end{tabular}

Differentation of motoneuron electrical properties was delayed in the presence of TTX (1 $\mu$ M). After 1 week in culture, motoneuron differentiation was slower in spinal cord explants cultured in TTX-containing medium (E15 + $1 \mathrm{Wk}$, TTX) than in explants cultured in normal medium (E15 $+1 \mathrm{Wk}$, normal). However, during that time motoneuron action potential threshold significantly decreased and maximum rate of rise increased compared to E15 motoneurons. Only after 3 weeks in medium containing TTX, motoneuron properties were similar to those of motoneurons cultured for 1 week in normal medium. Data are presented as mean $\pm \mathrm{SE} ; n$, number of motoneurons.

*Significantly different from $\mathrm{E} 15+1 \mathrm{Wk}(p<0,001)$.

**Significantly different from $\mathrm{E} 15+1 \mathrm{Wk}(p<0.05)$.

$\dagger \mathrm{E} 15+1-3 \mathrm{Wk}$, TTX which were significantly different from E15 $(p<0.001)$.

$\ddagger$ E15 + 1-3 Wk, TTX which were significantly different from E15 $(p<0.05)$. 


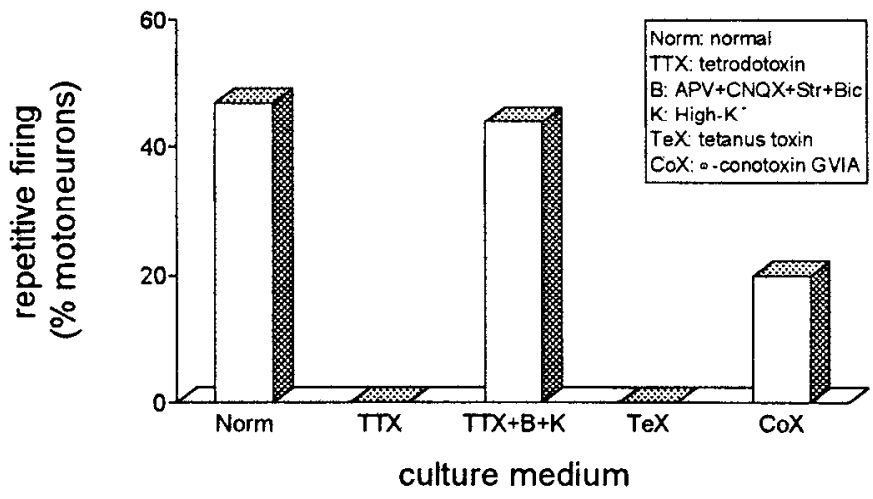

Figure 6. A histogram of the percentage of motoneurons firing repetitively after one weck in media containing blockers of voltage-gated channels and antagonists of amino acids receptors. In normal medium (Norm), 47\% of motoneurons fired repetitively $(n=21)$, while none of them was capable of generating repetitive action potentials in

TTX-containing medium $(1 \mu \mathrm{M}, n=9)$. High extracellular $\mathrm{K}^{+}(K, 20$ $\mathrm{mM}$ ) reversed the effect of TTX, and $44 \%$ of motoneurons fired repetitively $(T T X+B+K, n=9)$. Motoneurons in spinal cord explants cultured in the presence of tetanus toxin (TeX,2 $\mu \mathrm{g} / \mathrm{ml}, n=8)$ failed to generate a train of action potentials, and only $20 \%$ of motoneurons fired repetitively in medium containing $\omega$-conotoxin GVIA $(\mathrm{CoX}, 1 \mu \mathrm{M}, n$ $=10)$.

a basic rate of neuronal development, were preserved in culture. Two such potential factors are CNTF and NGF which were added to the culture medium to increase neuronal survival (Arakawa et al., 1990; Sendtner et al., 1990). However, CNTF and NGF alone were not sufficient to sustain the basic rate of differentiation, and presynaptic release of other neurotrophic factors was essential for the development of motoneuron properties.

The faster development of spinal motoneurons in vivo was probably regulated by neurotrophic factors, which were partially absent in culture. Substances which are required to prompt neu- ronal survival and growth are released from afferent inputs and target tissues (Cunningham, 1982; Dohrmann, 1987; Oppenheim et al., 1988, 1992; Martinou et al., 1989), and may facilitate motoneuron development in vivo. It is evident that exogenous application of neurotrophic factors facilitates neuronal development in vitro (Wright et al., 1992), and endogenous neurotrophic factors may have similar effects in vivo.

The decrease in action potential threshold is temporally correlated with the formation of sensorimotor synapses and neuromuscular junctions (Ziskind-Conhaim et al., 1988, 1990). These findings imply that in motoneurons developing in vivo, the newly formed synapses contributed to the reduced action potential threshold. However, it is unlikely that either excitatory or inhibitory synaptic transmission influenced the rate of its development, because chronic inhibition of glutamate-, glycine-, and $\mathrm{GABA}_{\mathrm{A}}$-mediated transmission did not prolong the delayed maturation of action potential threshold.

The time course of development of motoneuron excitability in vitro parallels that in vivo, despite the slow changes in motoneuron electrical properties. The increased probability of generating a sustained train of action potentials results from developmentally regulated changes in voltage-gated inward and outward currents (O'Dowd et al., 1988; McCobb et al., 1990; Ziskind-Conhaim, 1993b, 1994b). In spinal cord explants, the time course of these changes was at least partially regulated by $\mathrm{Ca}^{2+}$ dependent presynaptic release of neurotrophic factors. The increased excitability was independent of anterograde and retrograde inputs from the DRG and muscles, and was not modulated by segmental excitatory and inhibitory synaptic transmission. However, the regulation of neuronal excitability was partially dependent on the presence of the muscle in dissociated mouse DRG neurons, which are deprived of complex cell-cell interaction (Chen et al., 1987).

Contrary to developing rat spinal neurons, the maturation of

Table 4. Differentiation of motoneuron electrical properties was independent of glutamatemediated synaptic transmission

\begin{tabular}{|c|c|c|c|c|}
\hline Culture medium & $\begin{array}{l}\text { Resting } \\
\text { potential }(\mathrm{mV})\end{array}$ & $\begin{array}{l}\text { Input } \\
\text { resistance }(\mathrm{M} \Omega)\end{array}$ & $\begin{array}{l}\text { Threshold } \\
\text { potential }(\mathrm{mV})\end{array}$ & $\begin{array}{l}\text { Max, rate o } \\
\text { rise }(\mathrm{V} / \mathrm{sec})\end{array}$ \\
\hline $\begin{array}{r}\text { Normal } \\
2 \mathrm{Wk}\end{array}$ & $\begin{array}{l}-63.0 \pm 0.9 \\
(n=22)\end{array}$ & $105.4 \pm 5.2$ & $-40.0 \pm 0.6$ & $34.8 \pm 2.2$ \\
\hline $\begin{array}{l}\mathrm{APV}+\mathrm{CNQX} \\
2 \mathrm{Wk}\end{array}$ & $\begin{array}{l}-62.8 \pm 0.5 \\
(n=22)\end{array}$ & $103.1 \pm 5.0$ & $-41.5 \pm 0.6$ & $30.7 \pm 1.5$ \\
\hline $\begin{array}{l}\text { Strychnine }+ \text { bicuculline } \\
2 \mathrm{Wk}\end{array}$ & $\begin{array}{l}-62.7 \pm 0.9 \\
(n=7)\end{array}$ & $113.6 \pm 12.1$ & $-39.9 \pm 2.4$ & $33.0 \pm 1.8$ \\
\hline $\begin{array}{l}\text { TTX }+B \\
\text { I Wk }\end{array}$ & $\begin{array}{l}-58.0 \pm 0.9 * \\
(n=6)\end{array}$ & $133.8 \pm 15.2$ & $-35.7 \pm 1.5^{* *}$ & $15.3 \pm 2.0^{*}$ \\
\hline $\begin{array}{l}\mathrm{APV}+\mathrm{CNQX} \\
1 \mathrm{Wk}\end{array}$ & $\begin{array}{l}-62.5 \pm 0.9 \\
(n=11)\end{array}$ & $122.7 \pm 7.4$ & $-39.1 \pm 0.6$ & $28.8 \pm 2.7$ \\
\hline $\begin{array}{r}\text { MCPG } \\
1 \mathrm{Wk}\end{array}$ & $\begin{array}{l}-62.6 \pm 0.7 \\
(n=9)\end{array}$ & $149.2 \pm 17.4$ & $-39.7 \pm 1.4$ & $23.9 \pm 2.7$ \\
\hline
\end{tabular}

Blocking glutamate, glycine, and GABA receptors for $1-2$ weeks did not affect the time course of motoneuron development. Glutamate-mediated excitatory potentials were blocked by APV $(20 \mu M)$ and CNQX (10 $\mu M)$, but motoneuron differentiation was not delayed in their presence. Similarly, spinal cord incubation in the presence of strychnine $(10 \mu \mathrm{M})$ and bicuculline $(20 \mu \mathrm{M})$, which blocked glycine- and $\mathrm{GABA}_{\mathrm{A}}$-mediated inhibitory potentials, had no effect on motoneuron development. A combination of TTX $(1 \mu \mathrm{M})$ and antagonists of amino acid receptors (B: APV, CNQX, strychnine, and bicuculline) was effective in delaying motoneuron differentiation. Blocking metabotropic glutamate receptors with MCPG $(500 \mu \mathrm{M})$ did not influence the rate of changes in motoneuron electrical properties. Data are from motoneurons cultured for $1-2$ weeks. Data are presented as mean $\pm S E ; n$, number of motoneurons.

* Significantly different from motoneurons cultured for 1 week in medium containing APV and CNQX $(p<0.01)$.

**: Significantly different from motoneurons cultured for 1 week in medium containing APV and CNQX $(p<0.05)$. 
Table 5. Blocking synaptic release delayed the differentiation of motoneuron electrical properties

\begin{tabular}{lllll} 
Culture medium & $\begin{array}{l}\text { Resting potential } \\
(\mathrm{mV})\end{array}$ & $\begin{array}{l}\text { Input resistance } \\
(\mathrm{M} \Omega)\end{array}$ & $\begin{array}{l}\text { Threshold potential } \\
(\mathrm{mV})\end{array}$ & $\begin{array}{l}\text { Max. rate of } \\
\text { rise (V/sec) }\end{array}$ \\
\hline Normal & $\begin{array}{l}-63.0 \pm 0.6 \\
(n=21)\end{array}$ & $122.1 \pm 7.3$ & $-39.0 \pm 0.7$ & $26.9 \pm 1.3$ \\
TTX & $\begin{array}{l}-57.2 \pm 1.8^{*} \\
(n=9)\end{array}$ & $130.4 \pm 8.9$ & $-36.0 \pm 1.1^{* *}$ & $13.3 \pm 1.2^{*}$ \\
TTX + B & $\begin{array}{l}-61.4 \pm 1.0 \\
\quad+\text { high-K }\end{array}$ & $137.1 \pm 13.6$ & $-39.7 \pm 0.4$ & $23.8 \pm 1.5$ \\
Tetanus toxin & $\begin{array}{l}-58.6 \pm 0.9^{*} \\
(n=8)\end{array}$ & $122.9 \pm 12.2$ & $-33.1 \pm 0.7^{*}$ & $13.0 \pm 0.8^{*}$ \\
w-Conotoxin & $\begin{array}{l}-57.8 \pm 0.3^{*} \\
(n=10)\end{array}$ & $127.0 \pm 8.7$ & $-31.4 \pm 0.8^{*}$ & $15.5 \pm 1.1^{*}$
\end{tabular}

Differentiation of motoneuron electrical properties in the continuous presence of various substances that either facilitated or blocked synaptic release. Culturing spinal cord explants in high extracellular $\mathrm{K}^{+}(20 \mathrm{~mm})$ reversed TTX-induced delayed differentiation. The properties of motoneurons cultured in the presence of TTX, solution B and high- $\mathrm{K}^{*}$ were similar to those of motoneurons cultured in normal medium. Both tetanus toxin $(2 \mu \mathrm{g} / \mathrm{ml})$ and $\omega$-conotoxin GVIA $(1 \mu \mathrm{M})$ prolonged the delayed development of motoneuron electrical properties. Spinal cord explants were cultured for 1 week. Data are presented as mean $\pm \mathrm{SE} ; n$. number of motoneurons.

*Significantly different from motoneurons cultured in normal medium $(p<0.001)$.

** Significantly different from motoneurons cultured in normal medium $(p<0.05)$.

voltage-gated currents in Xenopus spinal neurons requires nei ther trophic factors nor complex cell-cell interactions, because the developmental changes in these currents are similar in dissociated neurons in primary cultures and in neurons developing in vivo (Desarmenien et al., 1993). Moreover, a similar pattern of differentiation occurs in single Xenopus neurons maintained in isolation in a simple culture medium (Henderson and Spitzer, 1986), indicating that cell contacts and extracellular factors are not required for the differentiation of the ionic currents.

\section{Blocking synaptic release delayed motoneuron differentiation}

It is generally assumed that pre- and postsynaptic factors are involved in the mechanisms underlying activity-dependent regulation of neuronal differentiation and synaptic plasticity. Our findings that TTX, tetanus toxin, and $\omega$-conotoxin delayed motoneuron development suggested that $\mathrm{Ca}^{2+}$-mediated synaptic release played an important role in the development of motoneuron excitability and electrical properties. It is conceivable that what appeared as delayed maturation resulted from toxin-induced selective elimination of the fast developing motoneurons. Based on this scenario, the delayed excitability after one week exposure to the toxins resulted from degeneration of half the population of motoneurons that acquired the ability to fire repetitively. TTX induces cell death in cultures of dissociated mouse spinal neurons (Bergey et al., 1981), and neurons and glia from the rat cerehral cortex (Ramakers et al., 1991), but it is unknown whether it randomly affects all cells or selectively induces degeneration of cells at advanced differentiating stages. It is unlikely that $\omega$-conotoxin had similar action, because unlike TTX and tetanus toxin, $20 \%$ of the motoneruons generated repetitive firing after 1 week exposure to the toxin.

The possible contribution of postsynaptic mechanisms to motoneuron differentiation was not examined in this study, but our findings suggested that activation of glutamate, glycine, and GA$\mathrm{BA}_{\mathrm{A}}$ receptors was not necessary for the development of motoneuron electrical properties. The NMDA subtype of glutamate receptor has been linked to activity-dependent mechanisms regulating synaptic plasticity in the adult spinal cord (Lewin et al., 1994), and expression of a proteoglycan on spinal motoneurons developing in vivo (Kalb and Hockfield, 1990). Similarly, activation of NMDA receptors plays an important role in the formation of synaptic contacts in dissociated spinal and DRG neurons (Nelson et al., 1989). Our findings that blocking NMDA receptors did not prolong the delayed differentiation of motoneuron electrical properties indicated that the development of these properties was independent of activation of NMDA receptors and the resulting $\mathrm{Ca}^{2+}$ influx.

Our study indicated that $\mathrm{Ca}^{2+}$-dependent synaptic release of some factors was necessary for normal rate of development. However, these factors did not include the excitatory and inhibitory neurotransmitters glutamate, glycine, and GABA. The release of neurotrophic factors other than neurotransmitters is probably responsible for the inductive role of synaptic contacts in regulating receptor synthesis in dissociated chick neurons (O'Brien and Fischbach, 1986), and motoneurons developing in vivo (Gao and Ziskind-Conhaim, 1993a). The regulatory effects may be exerted directly on motoneurons or indirectly via action on glial cells. An indirect action has been demonstrated in dissociated spinal cordDRG neurons, in which the release of vasoactive intestinal peptide (VIP) promotes neuronal survival (Brenneman, 1985). The effect of VIP is mediated via its interaction with astroglial cells, which triggers the release of neurotrophic factors that increase neuronal survival (Brenneman et al., 1987).

\section{References}

Aosaki N, Kasai H (1989) Characterization of two kinds of high-voltage-activated $\mathrm{Ca}$-channel currents in chick sensory neurons. Differential sensitivity to dihydropyridines and $\omega$-conotoxin GVIA. Pfluegers Arch 414:150-156.

Arakawa Y, Sendtner M, Thoenen H (1990) Survival effect of ciliary neurotrophic factor (CNTF) on chick embryonic motoneurons in culture: comparison with other neurotrophic factors and cytokines. J Neurosci 10:3507-3515.

Bergey GK, Fitzgerald SC, Schrier BK, Nelson PG (1981) Neuronal maturation in mammalian cell culture is dependent on spontaneous electrical activity. Brain Res 207:49-58.

Brenneman DE, Eiden LE, Siegel RE (1985) Neurotrophic action of VIP on spinal cord cultures. Peptides 6:35-39.

Brenneman DE, Neale EA, Foster GA, d'Autremont SW, Westbrook GL (1987) Nonneuronal cells mediate neurotrophic action of vasoactive intestinal peptide. Cell Biol 104:1603-1610. 
Chen G-g, Cole AE, MacDermott AB, Lange GD, Barker JL (1987) The influence of skeletal muscle on the electrical excitability of dorsal root ganglion neurons in culture. J Neurosci 7:2412-2422.

Cox DH, Dunlap K (1992) Pharmacological discrimination of N-type from L-type calcium current and its selective modulation by transmitters. J Neurosci 12:906-914.

Crain SM, Peterson ER (1963) Bioelectric activity in long-term cultures of spinal cord tissue. Science 141:427-429.

Cunningham TJ (1982) Naturally occurring neuron death and its regulation by developing neural pathways. Int Rev Cytol 74:163-186.

Desarmenien, M, Clendening, B, Spitzer, NC (1993) In vivo development of voltage-dependent ionic currents in embryonic Xenopus spinal neurons. J Neurosci 13:2575-2581.

Dohramnn U, Edgar D, Thoenen H (1987) Distinct neurotrophic factors from skeletal muscle and the central nervous system act synergistically to support the survival of cultured embryonic spinal motor neurons. Dev Biol 124:145-152.

Ealun SA, Janle DE, Jones PLStJ, Purter RHP, Pook PC-K, Sunter DC, Udvarhelyi PM, Roberts PJ, Salt TE, Watkins JC (1993) Competitive antagonism at metabotropic glutamate receptors by (S)-4-carboxyphenylglycine and (RS)- $\alpha$-methyl-4-carboxyphenylglycine. Eur J Pharmacol 244:195-197.

Fields RD, Neale EA, Nelson PG (1990) Effects of patterned electrical activity on neurite outgrowth from mouse sensory neurons. J Neurosci 10:2950-2964.

Fulton BP, Walton K (1986) Electrophysiological properties of neonatal rat motoneurons studied in vitro. J Physiol (Lond) 370:651-678.

Gao B-X, Ziskind-Conhaim L (1993a) Development of chemosensitivity in serotonin-deficient spinal cords of rat embryos. Dev Biol 158: $79-89$.

Gao B-X, Ziskind-Conhaim L (1993b) Development of repetitive firing in spinal motoneurons of newborn rats. Soc Neurosci Abstr 19:984.

Gao B-X, Ziskind-Conhaim L (1994a) Development of glycine- and GABA-gated currents in motoneurons of rat spinal cord. J Neurophysioi, in press.

Gao B-X, Ziskind-Conhaim L (1994b) Development of voltage-gated currents in rat spinal motoneurons. Soc Neurosci Abtst 20:791.

Gruner W, Silva LR (1994) Omega-conotoxin sensitivity and presynaptic inhibition of glutamatergic sensory neurotransmission in vitro. J Neurosci 14:2800-2808.

Habermann E, Dreyer F (1986) Clostridial neurotoxins: handling and action at the cellular and molecular level. Curr Top Microbiol Immunol 129:93-179.

Henderson LP, Spitzer NC (1986) Autonomous differentiation of neurons and muscle cells in single cell cultures. Dev Biol 113:381-387.

Hochner B, Spira ME (1987) Preservation of motoneuron electrical characteristic during postembryonic growth. J Neurosci 7:261-270.

Jahr CE, Yoshioka K (1986) Ia afferent excitation of motoncuroncs in the in vitro new-born rat spinal cord is selectively antagonized by kynurenate. J Physiol (Lond) 370:515-530.

Jiang ZG, Shen E, Dun NJ (1990) Excitatory and inhibitory transmission from dorsal root afferents to neonate rat motoneuorns in vitro. Brain Res 535:110-118.

Kalb RG, Hockfield S (1990) Large diameter primary afferentinput is required for expression of the CAT-301 proteoglycan on the surface of motor neurons. Neuroscience 34:391-401.

Kudo N, Yamada T (1985) Development of the monosynaptic stretch reflex in the rat: an in vitro study. J Physiol (Lond) 369:127-144.

Kudo N, Yamada T (1987) Morphological and physiological studies of development of the monosynaptic reflex pathway in the rat lumbar spinal cord. J Physiol (Lond) 389:441-459.

Lewin GK, Mckintosh E, McMahon SB (1994) NMDA receptors and activity-dependent tuning of the receptive fields of spinal cord neurons. Nature 369:482-485.

MacDermott AB, Westbrook GL (1986) Early development of voltagedependent sodium currents in cultured mouse spinal cord neurons. Dev Biol 113:317-326.

McCleskey EW, Fox AP, Feldman DH, Cruz LJ, Olivera BM, Tsien RW, Yoshikami D (1987) $\omega$-Conotoxin: direct and persistent blockade of specific types of calcium channels in neurons but not muscle. Proc Natl Acad Sci USA 84:4327-4331.

McCobb DP, Best PM, Beam KG (1990) The differentiation of excitability in embryonic chick limb motoneurons. J Neurosci 10:29742984.
Martin DL (1992) Synthesis and release of neuroactive substances by glial cells. Glia 5:81-94.

Martinou JC, LeVan Thai A, Cassar G, Roubinet FM, Weber J (1989) Characterization of two factors enhancing choline acetyltransferase activity in cultures of purified rat motoneurons. J Neurosci 9:36453656.

Martinou J-C, Martinou I, Kato AC (1992) Cholinergic differentiation factor $(\mathrm{CDF} / \mathrm{LIF})$ promotes survival of isolated rat embryonic motoneurons in vitro. Neuron 8:737-744.

Nelson PG, Fields D, Yu C, Neale EA (1990) Mechanisms involved in activity-dependent synapse formation in mammalian central nervous system cell cultures. J Neurobiol 21:138-156.

O'Brien RJ, Fischbach GD (1986) Modulation of embryonic chick motoneuron glutamate sensitivity by interneurons and agonists. J Neurosci 6:3290-3296.

Oppenheim RW, Haverkamp LJ, Prevette D, McManaman JL, Appel SH (1988) Reduction of naturally occurring motoneuron death in the chick embryo in vivo by a target-derived neurotrophic factor. Science 240:919-922.

Oppenheim RW, Yin QW, Prevette D, Yan Q (1992) Brain-derived neurotrophic factor rescues developing avian motoneurons from cell death. Nature 271:364-366.

Pinco M, Lev-Tov A (1993) Synaptic excitation of alpha-motoneurons by dorsal root afferents in the neonatal rat spinal cord. J Neurophysiol 70:406-417

Ramakers GJA, Raadsheer FC, Corner MA, Ramaekers FCS, Leeuwen FW (1990) Development of neurons and glial cells in cerebral cortex, cultured in the presence or absence of bioelectric activity: morphological observations. Eur J Neurosci 3:140-153.

Redmond LJ, Ziskind-Conhaim L, Xie H, Hockfield S (1994) Primary afferent innervation in an in vitro spinal cord system. Soc Neurosci Abstr 20:662

Saito K (1979) Development of spinal reflexes in the rat fetus studied in vitro. J Physiol (Lond) 294:581-594.

Seebach BS, Ziskind-Conhaim L (1994) Formation of transient inappropriate sensorimotor synapses in developing rat spinal cord. J Neurosci $14: 4520-4528$

Sendtner M, Kreutzberg GW, Thoenen H (1990) Ciliary neurotrophic factor prevents the degeneration of motor neurons after axotomy. $\mathrm{Na}$ ture 345:440-441.

Smith CL, Hollyday M (1983) The development and postnatal organization of motor nuclei in the rat thoracic spinal cord. J Comp Neurol 220:16-28.

Snider WD, Zhang L, Yusoof S, Gorukanti N, Tsering C (1992) Interactions between dorsal root axons and their target motor neurons in developing mammalian spinal cord. J Neurosci 12:3494-3508.

Spenger C, Braschler U, Streit J, Luscher H-R (1991) An organotypic spinal cord-dorsal root ganglion-skeletal muscle coculture of embryonic rat. I. The morphological correlates of the spinal reflex arc. Eur J Neurosci 3:1037-1053.

Stoppini L, Buchs P-A, Muller D (1991) A simple method for organotypic cultures of nervous tissue. J Neurosci Methods 37:173-182.

Streit J, Luscher H-R (1992) Miniature excitatory postsynaptic potentials in embryonic motoneurons grown in slice cultures of spinal cord, dorsal root ganglia and skeletal muscle. Exp Brain Res 89:453-458.

Streit J, Spenger C, Luscher H-R (1991) An organotypic spinal corddorsal root ganglion-skeletal muscle coculture of embr yonic rat. II. Functional evidence for the formation of spinal reflex arcs in vitro. Eur J Neurosci 3:1054-1068.

'Takahashi T' (1978) Intracellular recording from visually identified motoneurons in rat spinal cord slices. Proc R Soc Lond [Biol] 202:417421.

Takahashi T (1984) Inhibitory miniature synaptic potentials in rat motoneurons. Proc R Soc Lond [Biol] 221:103-109.

Tarrade T, Crain SM (1978) Regional localization of patterned spontaneous discharges during maturation in culture of fetal medulla and spinal cord explants. Dev Neurosci 1:119-132.

Walton K, Fulton BP (1986) Ionic mechanisms underlying the firing properties of rat neonatal motoneurons studied in vitro. Neuroscience 19:669-683.

Williamson LC, Fitzgerald SC, Neale EA (1992) Differential effects of tetanus toxin on inhibitory and excitatory neurotransmitter release from mammalian spinal cord cells in culture. J Neurochem 59:21482157.

Wright EM, Vogel KS, Davies AM (1992) Neurotrophic factors pro- 
mote the maturation of developing sensory neurons before they become dependent on these factors for survivial. Neuron 9:139-150.

Wu W-L, Ziskind-Conhaim L, Sweet MA (1992) Early development of glycine and GABA mediated synapses in rat spinal cord. J Neurosci $12: 3935-3945$.

Xie H, Ziskind-Conhaim L (1993) Differentiation of motoneuron electrical properties in organotypic cultures of rat spinal cord. Soc Neurosci Abstr 19:1506.

Xie H, Ziskind-Conhaim L (1994) Activity dependent differentiation of motoneuron electrical properties. Soc Neurosci Abstr 20:792.
Ziskind-Conhaim L (1988) Electrical properties of motoneurons in the spinal cord of rat embryos. Dev Biol 128:21-29.

Ziskind-Conhaim L (1990) NMDA receptors mediate poly- and monosynaptic potentials in motoneurons of rat embryos. J Neurosci 10: $125-135$.

Ziskind-Conhaim L, Presley S (1991) Reinnervation of developing rat muscle by non-axotomized motoneurons. J Comp Neurol 313:725734.

Ziskind-Conhaim L, Seebach BS, Gao B-X (1993) Changes in serotonin-induced potentials during spinal cord development. I Neurophysiol 67:1338-1349. 